\title{
A Study to Assess the Knowledge and Practice on Water Borne Diseases and its Prevention Mothers of Under Five Children
}

\author{
Varalakshmi. ( $^{*}$, Mahalakshmi $\mathrm{R}^{2}$, Prashanth $\mathrm{K}^{2}$ \\ ${ }^{1}$ Department of Medical Surgical Nursing, Saveetha College of Nursing, SIMATS, Chennai, India \\ ${ }^{2}$ B.Sc (N) IV Year, Saveetha College of Nursing, SIMATS, Chennai, India
}

DOI: $10.36348 /$ sjnhc.2020.v03i11.011

| Received: 05.11.2020 | Accepted: 16.11.2020 | Published: 28.11.2020

*Corresponding author: Varalakshmi E

Abstract

Water is the most indispensable nature resource in the world for every living being waterborne diseases most commonly are transmitted in contaminated fresh water. Infection commonly results during bathing, washing, drinking, in the preparation of food, or the consumption of food thus infected. Objectives: To assess the Level of Knowledge Regarding Water Borne Diseases and its Prevention among mothers of Under Five Children. To find the association of knowledge among mothers of under five children with selected demographic variables. Methodology: A quantitative approach with Descriptive research design was used. The independent variable in this study Water borne disease and its prevention. The dependent variables in this study are Knowledge of mothers of under five children on waterborne diseases and its prevention. A study was conducted in Erayamangalm village, Thiruvallur District The sample size consists of 60 under five children mothers. Who fulfils the inclusion criteria were selected by Convenient sampling technique sampling technique. Results: Major findings of the study were overall mean score is 26.83 with a mean percentage $89.43 \%$ and standard deviation 2.93. A significant relationship was observed between education, food pattern and source of information with the knowledge. Whereas age, occupation, monthly income and type of family do not show any relationship of mothers regarding water borne diseases and its prevention. Result of this study reveals that $8.33 \%$ of mothers were having moderate knowledge of water borne diseases and its prevention and $91.67 \%$ of mothers were having adequate knowledge on water borne diseases and its prevention. Conclusion: Waterborne diseases being the major health problem in children below five years of age and most of the mothers are unaware about its first aid home management and leads to complications. The study was done to assess the knowledge and practice on prevention of waterborne diseases among mothers of children below five years of age.

Keywords: Knowledge, prevention, water borne diseases, under five children, mothers, rural community.

Copyright $\odot \mathbf{2 0 2 0}$ The Author(s): This is an open-access article distributed under the terms of the Creative Commons Attribution 4.0 International License (CC BY-NC 4.0) which permits unrestricted use, distribution, and reproduction in any medium for non-commercial use provided the original author and source are credited.

\section{INTRODUCTION}

Water is the most indispensable nature resource in the world for every living being. The entire life-support systems are dependent upon this vital resource. It is most important to all as it is directly consumed by all living entities [1]. water-related infectious diseases into two categories. Waterborne infectious diseases, such as diarrhea, are linked to poor sanitation, inadequate hygiene, ingestion of and contact with unsafe water, and lack of access to adequate amounts of safe water [2, 3].

The most common and wide spread health risk associated with drinking water is its contamination, either directly or indirectly by human or animal excreta. Drinking contaminated water or using it in food preparation may cause infection [4].
Clean water is a pre-requisite for reducing the spread of waterborne diseases. It is well Recognized that the prevalence of waterborne disease can be greatly reduced by provision of clean drinking water and safe disposal of faeces[5].

Various forms of waterborne diarrheal disease probably are the most prominent examples, and affect mainly children in developing countries; according to the World Health Organization, such diseases account for an estimated $4.1 \%$ of the total daily global burden of disease, and cause about 1.8 million human deaths annually [6].

The World Health Organization estimates that $88 \%$ of that burden is attributable to unsafe water 
supply, sanitation and hygiene Microorganism causing diseases that characteristically are waterborne prominently include protozoa and bacteria many of which are intestinal parasites, or invade the tissues or circulatory system through walls of the digestive tract [7].

Various other waterborne diseases are caused by viruses. (In spite of philosophical difficulties associated with defining viruses as "organisms", it is practical and convenient to egard them as microorganisms in this connection) Yet other important classes of water-borne diseases are caused by metazoan parasites. Typical examples include certain Nematodes, that is to say "roundworms". As an example of waterborne Nematode infections, one important waterborne nematodal disease is Dracunculiasis [8,9].

The children consist about $20 \%$ of our total population are prone to get infections from different sources like food, water, flies, fomites and polluted environment. Allaspects of child care are looked after by the mother only. So mother have prime role in the prevention of water borne diseases [10].

Waterborne diseases represent a major burden on human health worldwide. Every year, 1.8 million people die from diarrheal diseases, of which 1.5 million are children under the age of 5. Access to safe drinking water, basic sanitation and proper hygiene education could not only prevent diarrheal diseases by nearly $90 \%$ but furthermore lead to improved health, poverty reduction and socioeconomic development. Goal 7 of the Millennium Development goals (MDG) set by the United Nations in 2000 is to halve by 2015 the proportion of people without sustainable access to safe drinking water and basic sanitation $[11,12]$.

A purpose of the study (1) to assess the Level of Knowledge Regarding Water Borne Diseases and its Prevention among mothers of Under Five Children. (2) To find the association of knowledge among mothers of under five children with selected demographic variables.

\section{METHODS AND MTERIALS}

A quantitative approach with Descriptive research design was used to conduct the study in Erayamangalm village, Thiruvallur District. 60 samples were selected by using a convenience sampling technique. The inclusion criteria for sample collection, the mothers who have children between the age of six months to five years are available in Erayamangalm village, mothers of under five children who are willing to participate in the study. The exclusion criteria were the samples those who are not available at the time of data collection, mothers who are having children more than five years of age group. The data collection period was done with prior permission from the principal of Saveetha College of nursing. The purpose of the study was explained to the samples with written informed consent was obtained from health authority officer in Erayamangalam village. The demographic data were collected by using a structured interview questionnaire and the level of knowledge was assessed regarding Water Borne Diseases and its Prevention among mothers of Under Five Children. Pearson's correlation coefficient was used to assess the level of knowledge regarding Water Borne Diseases and its Prevention among mothers of Under Five Children. Chi square was used association of relationship between overall knowledge on waterborne disease and its prevention on with socio demographic variables.

\section{RESULTS AND DISCUSSION Section A: Sample characteristics}

The majority of the mothers $(50 \%)$ were in the age group of $23-28$ years, $(31.67 \%)$ were in 18-22 years, $(18.33 \%)$ were in $29-34$ years of age.

According to the education majorities $(60 \%)$ of mothers have done S.S.L.C, $25 \%$ of them were graduates and $15 \%$ were illiterate.

As far as the occupational status the $58.33 \%$ mothers were on private jobs, $31.67 \%$ were house wives and $10 \%$ were doing government jobs.

Regarding the family income majorities $48.33 \%$ of them have monthly family income above $15,000-20,000,40 \%$ of them have family Income of $21,000-25,000$ and $11.67 \%$ of them have family income of less than 26,000 - 30,000. Among type of family the majority $51.67 \%$ belongs to single family, $45 \%$ belongs to joint family and $3.33 \%$ belongs tot nuclear family.

Among study the majority $88.33 \%$ were non vegetarian and $11.67 \%$ were vegetarian. Regarding source of information $45 \%$ gains knowledge through newspaper, $333.33 \%$ through T.V and $2 \%$ through Radio.

\section{Section-B: Assessment of level of knowledge regarding water borne disease and it is prevention among mother of fewer than five children:}

Table-1: Frequency and Percentage Distribution of Mothers According to level of knowledge

\begin{tabular}{|c|c|c|}
\hline Knowledge level & Frequency & Percentage \\
\hline Inadequate $(<50 \%)$ & 0 & 0 \\
\hline Moderate $(51-75 \%)$ & 5 & 58.33 \\
\hline Adequate $(>75 \%)$ & 55 & 91.67 \\
\hline
\end{tabular}


This table shows that frequency and percentage of level of knowledge among mothers regarding water borne diseases and its prevention. It shows that $8.33 \%$ of mothers were having moderate knowledge and $91.67 \%$ were having adequate knowledge regarding water borne diseases and its prevention.
This study was also supported by Kanimozhi. D [6]: has conducted study to assess the knowledge of mothers of under five children regarding selected water borne diseases in Kumaramangalam area under Namakkal district. The results of this study revealed that $60 \%$ of mothers were in the age group of 23-30 years. $90 \%$ were hindu, $40 \%$ were illiterate, $53.3 \%$ were house wives, $72 \%$ belong to nuclear family. $40 \%$ of subjects had monthly income less than Rs 5000.

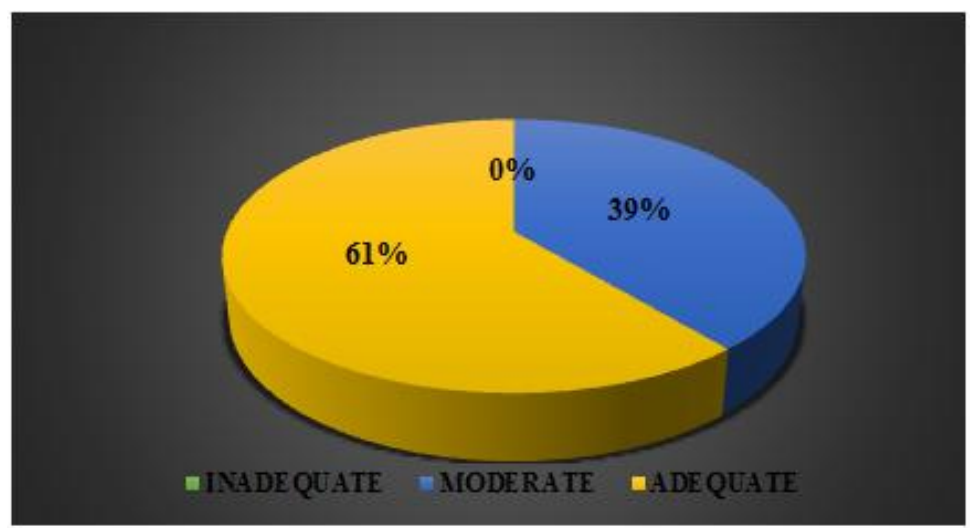

Fig-1: Frequency and Percentage Distribution of Mothers According to level of knowledge

\begin{abstract}
Section - C: Relationship between overall knowledge on waterborne disease and its prevention on with socio demographic variables of the mothers such as age, educational status, occupation, monthly incom, type of family income, food pattern and source of information:
\end{abstract}

The result obtained on chi square analysis of association between level of knowledge on water borne diseases and its prevention with demographic variables. Among the variables accounted the association of knowledge of mothers with demographic variables such as educational status of mother, food pattern, sources of information were statistically significant and age, occupation, monthly family income, type of family were not significant at $5 \%$ level with knowledge level.

The study supported by Sameeeksha [13]: Prevention of food and water borne disease involves healthy life style. It may reduce developing health problems in children. It becomes the Nurse's responsibility to stress out the importance of prevention of food and water borne diseases and urgency of receiving medical advice. The main aim of the study was to assess the knowledge regarding food and water borne diseases \& their prevention among students of a selected school at Pilkhuwa, Dist. Hapur, Uttar Pradesh. A descriptive design with stratifified random sampling method was adopted. The study was conducted in St. Xavier school of village Khera, Pilkhuwa on a sample size of 60 students in the age group of 10-15 years. The tools used to collect the data were demographic proforma and Self Structured Knowledge Questionnaire. Collected data was analyzed by using descriptive and inferential statistics. The study revealed that $76.67 \%$ of the students had moderate knowledge and $23.33 \%$ of the students had adequate knowledge regarding food and water borne disease $\&$ their Prevention.

\section{CONCLUSION}

Waterborne diseases being the major health problem in children below five years of age and most of the mothers are unaware about its first aid home management and leads to complications. The study was done to assess the knowledge and practice on prevention of waterborne diseases among mothers of children below five years of age. Among the variables accounted the association of knowledge of mothers with demographic variables such as educational status of mother, food pattern, sources of information were statistically significant and age, occupation, monthly family income, type of family were not significant at $5 \%$ level with knowledge level.

\section{ACKNOWLEDGEMENT}

We might want to stretch out our appreciation to the specialists of Saveetha College of Nursing and Saveetha Medical College Hospital for this examination.

\section{AUTHORS CONTRIBUTION}

All the creators effectively took part in crafted by study. All the writers read and affirmed the last composition.

\section{CONFLICTS OF INTEREST}

The creators proclaim no irreconcilable circumstance. 


\section{REFERENCES}

1. Rana, A. K. M. M. (2009). Effect of water, sanitation and hygiene Intervention in reducing self-reported waterborne diseases in rural Bangladesh. RED research report: Online.

2. Basavanthappa, B.T. (1998). Nursing Research. 1st ed. New Delhi: Jaypee brothers medical publishers; 24.

3. Rooney, R. M., Bartram, J. K., Cramer, E. H., Mantha, S., Nichols, G., Suraj, R., \& Todd, E. C. (2004). A review of outbreaks of waterborne disease associated with ships: evidence for risk management. Public health reports, 119(4), 435442.

4. Galbraith, N. S., Barrett, N. J., \& Stanwell- Smith, R. O. S. A. L. I. N. D. (1987). Water and Disease after Croydon: A Review of Water- borne and Water- associated Disease in the UK 193786. Water and Environment Journal, 1(1), 7-21.

5. Gupta, M. C. (2003). Textbook of Preventive and Social Medicine. 3rd ed. New Delhi: Jaypee publishers.

6. Kanimozhi. D. (2005). Has conducted study to assess the knowledge of mothers of fewer than five children regarding selected water borne diseases in Kumaramangalam area under Namakkal district.

7. Reynolds, K. A. (2004). Groundwater vulnerability to microbial contamination. Water Conditioning \& Purification, 56, 28-30.

8. Mabiza. (2009). An outbreak of dysentery in rural Zimbabwe. Journal of health and nutrition.

9. Marlow, D.R., Redding, B.A. (1998). 6th ed.1998: Textbook of Pediatric Nursing.

10. Narongsak Noosorn and prasit. (2000). Journal of American Water Works Association, 9; 24-43.

11. Park, K. (2005). Textbook of Preventive and Social Medicine. 15th ed. Banarsidas Bhanot publishers.

12. Rao, K.S.3rd ed. (2000). An Introduction to Community Nursing. New Delhi: B.J. Publishers.

13. Sameeeksha. (2018). Prevention of food and water borne disease involves healthy life style. Deshpande K, Kakkar R, Diwan V. Survey to assess quantity and quality of water and problems perceived by residents, Ujjain.

14. Yashoda, V, Hemavathy, V. (2014). Effectiveness of knowledge of selected water borne diseases among school children, NNJ, 3(4):39-40. 